\title{
Dabigatran versus Warfarin in the Treatment of Acute Venous Thromboembolism
}

\author{
Sam Schulman, M.D., Clive Kearon, M.D., Ajay K. Kakkar, M.D., \\ Patrick Mismetti, M.D., Sebastian Schellong, M.D., Henry Eriksson, M.D., \\ David Baanstra, M.Sc., Janet Schnee, M.D., and Samuel Z. Goldhaber, M.D., \\ for the RE-COVER Study Group*
}

A BSTRACT

From the Department of Medicine, McMaster University and Henderson Research Centre, Hamilton, ON, Canada (S. Schulman, C.K.); the Department of Hematology, Karolinska University Hospital, Stockholm (S. Schulman); Thrombosis Research Institute and Queen Mary University of London, London (A.K.K.); the Department of Vascular Pathology, Bellevue Hospital, Saint Etienne, France (P.M.); Medical Division 2, Municipal Hospital Friedrichstadt, Dresden, Germany (S. Schellong); the Department of Medicine, Sahlgrenska University Hospital-Östra, Gothenburg, Sweden (H.E.); Clinical Research, Boehringer Ingelheim, Alkmaar, the Netherlands (D.B.); Boehringer Ingelheim, Ridgefield, CT (J.S.); and Brigham and Women's Hospital, Harvard Medical School, Boston (S.Z.G.). Address reprint requests to Dr. Schulman at Thrombosis Service, HHS-General Hospital, 237 Barton St. East, Hamilton, ON L8L 2X2, Canada, or at schulms@mcmaster.ca.

*Members of the RE-COVER Study Group are listed in the Appendix.

This article (10.1056/NEJMoa0906598) was published on December 6, 2009, and was updated on February 22, 2010, at NEJM.org.

N Engl J Med 2009;361:2342-52.

Copyright (C) 2009 Massachusetts Medical Society.

\section{BACKGROUND}

The direct oral thrombin inhibitor dabigatran has a predictable anticoagulant effect and may be an alternative therapy to warfarin for patients who have acute venous thromboembolism.

\section{METHODS}

In a randomized, double-blind, noninferiority trial involving patients with acute venous thromboembolism who were initially given parenteral anticoagulation therapy for a median of 9 days (interquartile range, 8 to 11), we compared oral dabigatran, administered at a dose of $150 \mathrm{mg}$ twice daily, with warfarin that was dose-adjusted to achieve an international normalized ratio of 2.0 to 3.0. The primary outcome was the 6-month incidence of recurrent symptomatic, objectively confirmed venous thromboembolism and related deaths. Safety end points included bleeding events, acute coronary syndromes, other adverse events, and results of liver-function tests.

\section{RESULTS}

A total of 30 of the 1274 patients randomly assigned to receive dabigatran (2.4\%), as compared with 27 of the 1265 patients randomly assigned to warfarin (2.1\%), had recurrent venous thromboembolism; the difference in risk was 0.4 percentage points $(95 \%$ confidence interval [CI], -0.8 to 1.5 ; $\mathrm{P}<0.001$ for the prespecified noninferiority margin). The hazard ratio with dabigatran was 1.10 (95\% CI, 0.65 to 1.84). Major bleeding episodes occurred in 20 patients assigned to dabigatran $(1.6 \%)$ and in 24 patients assigned to warfarin (1.9\%) (hazard ratio with dabigatran, 0.82 ; $95 \%$ CI, 0.45 to 1.48), and episodes of any bleeding were observed in 205 patients assigned to dabigatran $(16.1 \%)$ and 277 patients assigned to warfarin $(21.9 \%$; hazard ratio with dabigatran, $0.71 ; 95 \% \mathrm{CI}, 0.59$ to 0.85 ). The numbers of deaths, acute coronary syndromes, and abnormal liver-function tests were similar in the two groups. Adverse events leading to discontinuation of the study drug occurred in $9.0 \%$ of patients assigned to dabigatran and in $6.8 \%$ of patients assigned to warfarin $(\mathrm{P}=0.05)$.

\section{CONCLUSIONS}

For the treatment of acute venous thromboembolism, a fixed dose of dabigatran is as effective as warfarin, has a safety profile that is similar to that of warfarin, and does not require laboratory monitoring. (ClinicalTrials.gov number, NCT00291330.) 
ENOUS THROMBOEMBOLISM AFFECTS 1 to 2 adults per 1000 annually and is the third most common cause of vascular death after myocardial infarction and stroke. ${ }^{1,2}$ The current standard treatment is rapidly acting parenteral anticoagulation for 5 to 7 days followed by at least 3 months of treatment with a vitamin $\mathrm{K}$ antagonist. ${ }^{3}$ Treatment with a vitamin $\mathrm{K}$ antagonist requires frequent monitoring of the international normalized ratio (INR), and multiple interactions of vitamin $\mathrm{K}$ antagonists with foods and other drugs have been reported. ${ }^{4}$

Dabigatran etexilate (hereafter termed dabigatran) is an orally available, potent, direct inhibitor of thrombin. It is rapidly converted by ubiquitous esterases to the active drug, is administered in fixed doses without the need for coagulation monitoring, is excreted by the kidney, and has a halflife of 12 to 17 hours. ${ }^{5}$ Dabigatran has similar efficacy and safety to enoxaparin for the prevention of venous thromboembolism in patients who have had elective hip or knee arthroplasty. ${ }^{6,7}$ Recently, dabigatran, as compared with warfarin, was shown to have superior safety with equivalent efficacy (when it was administered at a dose of $110 \mathrm{mg}$ twice daily), or superior efficacy with similar safety (when it was administered at a dose of $150 \mathrm{mg}$ twice daily), for the prevention of stroke in patients with atrial fibrillation. ${ }^{8}$ We compared dabigatran, administered at a dose of $150 \mathrm{mg}$ twice daily, with warfarin for the treatment of acute venous thromboembolism.

\section{METHODS}

\section{STUDY DESIGN}

In the RE-COVER study, a double-blind, doubledummy, randomized trial, we compared 6 months of treatment with dabigatran, at a fixed dose of $150 \mathrm{mg}$ twice daily, with dose-adjusted warfarin therapy, after initial parenteral anticoagulation. The study was funded, designed, and conducted, and the data analyzed, by Boehringer Ingelheim in conjunction with the steering committee, whose members vouch for the accuracy and completeness of the data and the analyses in this report. The members of the steering committee wrote the manuscript and made the decision to submit it for publication.

\section{STUDY PATIENTS}

Patients were recruited from 228 clinical centers in 29 countries. Patients 18 years of age or older who had acute, symptomatic, objectively verified proximal deep-vein thrombosis of the legs or pulmonary embolism and for whom 6 months of anticoagulant therapy was considered to be an appropriate treatment were potentially eligible. Exclusion criteria were duration of symptoms longer than 14 days, pulmonary embolism with hemodynamic instability or requiring thrombolytic therapy, another indication for warfarin therapy, recent unstable cardiovascular disease, a high risk of bleeding, liver disease with an aminotransferase level that was two times the local upper limit of the normal range, an estimated creatinine clearance of less than $30 \mathrm{ml}$ per minute, a life expectancy of less than 6 months, a contraindication to heparin or to radiographic contrast material, pregnancy or risk of becoming pregnant, or a requirement for long-term antiplatelet therapy ( $\leq 100 \mathrm{mg}$ of acetylsalicylic acid daily was acceptable). There were no weight restrictions. All patients provided written informed consent, and the institutional review board at each participating clinical center approved the study.

\section{RANDOM ASSIGNMENT AND TREATMENT}

Before randomization, the diagnosis of venous thromboembolism was established with the use of compression ultrasonography or venography of leg veins and ventilation-perfusion lung scanning, angiography, or spiral computed tomography of pulmonary arteries. Additional baseline examination of the initially nonexamined leg or legs with the use of compression ultrasonography and, in case of symptomatic deep-vein thrombosis, examination of the pulmonary arteries with the use of perfusion lung scanning or spiral computed tomography were required to be performed within 72 hours after randomization. We used a computergenerated randomization scheme with variable block sizes, stratified according to presentation (pulmonary embolism or deep-vein thrombosis without symptomatic pulmonary embolism) and the presence or absence of active cancer. Staff members at the clinical centers called an interactive voice-response system that randomly assigned subjects to one of the supplied medication kits. The treatment-group assignment was concealed from all the investigators and their staff at the coordinating center and the clinical centers and from the clinical monitors.

Patients were assigned in a 1:1 ratio to receive a fixed dose of dabigatran (150 mg twice daily taken orally) or warfarin. Initial treatment with 
an approved parenteral anticoagulant (generally unfractionated heparin administered intravenously or low-molecular-weight heparin administered subcutaneously) was usually started before random assignment. Warfarin or a placebo that looked identical to warfarin was generally started on the day of random assignment and was adjusted to achieve an INR of 2.0 to 3.0 on a point-of-care coagulometer that was programmed, in conjunction with the randomization schedule, to yield either a true INR or a sham INR ("singledummy phase"). Administration of dabigatran or a placebo that looked identical to dabigatran was initiated, and the parenteral anticoagulant was stopped, once the parenteral anticoagulant had been given for at least 5 days and the true or sham INR was recorded as 2.0 or higher on 2 consecutive days. The first dose of dabigatran was given within 2 hours before the time that the next dose of initial parenteral therapy would have been due or at the time of discontinuation of intravenous unfractionated heparin. Active dabigatran and warfarin-like placebo or active warfarin and dabigatran-like placebo were then given for 6 months ("double-dummy phase").

\section{FOLLOW-UP AND OUTCOME MEASURES}

Patients were assessed at 7 days and then monthly until 6 months and were told to contact their study site immediately if symptoms developed that were suggestive of venous thromboembolism or bleeding. An additional follow-up visit was scheduled for 30 days after completion of the study, unless the patient had discontinued the study drug before 6 months, had started open-label anticoagulant therapy, or had been enrolled in another trial. Symptoms suggestive of recurrent venous thromboembolism were evaluated with the use of the same diagnostic methods that had been used for the initial diagnosis. Bleeding was defined as major if it was clinically overt and if it was associated with a fall in the hemoglobin level of at least $20 \mathrm{~g}$ per liter, resulted in the need for transfusion of 2 or more units of red cells, involved a critical site, or was fatal. ${ }^{9}$ Less severe bleeding episodes were classified as minor and were subcategorized as clinically relevant bleeding (see the Supplementary Appendix, available with the full text of this article at NEJM.org) or nuisance bleeding. Other adverse events, results of liver-function tests and other laboratory measures, occurrence of acute coronary syndromes, and adherence (quantified by capsule counts) were routinely assessed. All suspected outcome events and deaths were classified by central adjudication committees, whose members were unaware of the treatment assignments.

\section{STATISTICAL ANALYSIS}

The trial was designed to determine whether 6 months of dabigatran therapy was as effective as 6 months of warfarin therapy (i.e., noninferior) and to compare the safety of the two treatments. The sample size was determined on the basis of an expected rate of the primary efficacy outcome of $2 \%$ at 6 months in each group and a requirement that the study would have $90 \%$ power to exclude a hazard ratio of 2.75 and an absolute increase in risk of 3.6 percentage points for the primary outcome with dabigatran, at a one-sided alpha level of 0.025 . These noninferiority margins were estimated to correspond to preservation of $57 \%$ (for assessment of hazard ratio) and $75 \%$ (for assessment of difference in risk) of the lower boundary of the $95 \%$ confidence interval for the efficacy of warfarin as compared with no anticoagulation, as assessed in four studies that compared discontinuing warfarin therapy at 4 to 6 weeks with continuing it for 3 to 6 months. ${ }^{10-13}$ We anticipated that the data from up to $20 \%$ of the randomly assigned patients might not be able to be analyzed. A sample size of 2550 patients, with 1275 in each group, and an expected total of 46 events satisfied these requirements. No formal interim analyses were planned or performed. The data and safety monitoring board monitored safety and efficacy end points.

The primary analysis for efficacy was a comparison between the groups of the time to the first occurrence of the composite end point of symptomatic venous thromboembolism or death associated with venous thromboembolism in the 6 months after random assignment, as assessed by the hazard ratio calculated with the use of the Cox model and the difference in risk calculated with the use of Kaplan-Meier estimates. Both summary statistics were adjusted for the initial presentation (i.e., pulmonary embolism or deep-vein thrombosis) and for the presence or absence of active cancer at baseline (the interaction between active cancer and symptomatic pulmonary embolism was also included in the Cox model).

We tested for noninferiority by comparing the upper boundary of the $95 \%$ confidence interval for the hazard ratio with the predefined margin of 2.75 and the upper boundary of the $95 \%$ con- 
fidence interval for the difference in risk with the predefined margin of 3.6 percentage points. If noninferiority was established by both criteria, testing for superiority of dabigatran was to be performed.

We analyzed efficacy according to a modified intention-to-treat principle, since patients who did not receive any study drug were excluded from all analyses, as was prespecified in the protocol. For safety analyses, including bleeding episodes, events were considered from the time of the first intake of the study drug to 6 days after the last intake of the study drug; these analyses were performed on the basis of the patient's actual treatment with the study drug. The 6-day period after the last intake of the study drug was not included in the analysis if patients started open-label anticoagulant therapy or if they were enrolled in the RE-MEDY study (ClinicalTrials.gov number, NCT00329238), a double-blind trial comparing dabigatran and warfarin for extended treatment of venous thromboembolism. All safety analyses and secondary efficacy analyses were predefined.

\section{RESULTS}

\section{PATIENTS}

From April 2006 through November 2008, a total of 2564 patients were randomly assigned to a study group; $78.5 \%$ of the patients were from Europe or North America. Seven patients in the dabigatran group and 18 in the warfarin group did not receive any study medication (4 did not meet the inclusion criteria for venous thromboembolism, 11 met the exclusion criteria, 5 withdrew consent, 4 never took the study drug, and 1 had another reason). A total of 1274 patients in the dabigatran group and 1265 in the warfarin group were included in the analysis of efficacy. One patient who was assigned to receive dabigatran mistakenly received warfarin during the entire study; this patient did not have any outcome event and was included as part of the warfarin group in the safety analysis. There were no significant differences between the groups in baseline characteristics (Table 1).

\section{TREATMENT AND FOLLOW-UP}

Parenteral anticoagulation was given for a mean of 10 days in both treatment groups. The details of the treatment given are shown in Table 1 . The mean number of INR values obtained in the war- farin group over the course of 6 months was 16 . The INR was in the therapeutic range $60 \%$ of the time (Table 1), improving from $53 \%$ during the first month to $66 \%$ during the last month. Overall, the INR was below the therapeutic range 21\% of the time and above the therapeutic range 19\% of the time. The study drug was stopped before 6 months in 204 patients $(16.0 \%)$ in the dabigatran group (126 because of an adverse event, 21 because of nonadherence, 9 because of loss to follow-up, 39 because of withdrawal of consent, and 9 for other reasons) and in 183 patients (14.5\%) in the warfarin group (102 because of an adverse event, 35 because of nonadherence, 6 because of loss to follow-up, 36 because of withdrawal of consent, and 4 for other reasons). The observation time for the assessment of efficacy was shorter than 6 months in 101 patients (7.9\%) in the dabigatran group (47 because of an adverse event, 13 because of nonadherence, 16 because of loss to follow-up, 22 because of withdrawal of consent, and 3 for other reasons) and 97 patients (7.7\%) in the warfarin group ( 40 because of an adverse event, 20 because of nonadherence, 11 because of loss to follow-up, 25 because of withdrawal of consent, and 1 for other reasons). Although it was intended that all patients who stopped the study drug owing to an adverse event or who were considered to show nonadherence would complete 6 months of follow-up, this did not always occur. After completion of 6 months in this trial, 506 patients in the dabigatran group and 541 patients in the warfarin group gave additional informed consent and were randomly assigned a second time to receive treatment with dabigatran or warfarin as extended secondary prophylaxis, as part of the double-blind RE-MEDY study.

\section{EFFICACY}

The investigators suspected that recurrent venous thromboembolism had occurred or that a death had been related to recurrent venous thromboembolism in 134 patients in the dabigatran group and 130 patients in the warfarin group. After central adjudication, the primary outcome for efficacy was confirmed in 30 patients in the dabigatran group $(2.4 \%$ of all patients in the dabigatran group) and 27 patients in the warfarin group (2.1\% of all patients in the warfarin group). The difference in risk was 0.4 percentage points $(95 \%$ confidence interval [CI], -0.8 to 1.5 ; hazard ratio, 1.10 ; $95 \%$ CI, 0.65 to 1.84 ) (Fig. 1). As com- 


\begin{tabular}{|c|c|c|c|}
\hline Characteristic & $\begin{array}{l}\text { Dabigatran } \\
(\mathrm{N}=1273)\end{array}$ & $\begin{array}{l}\text { Warfarin } \\
(N=1266)\end{array}$ & $P$ Value \\
\hline Age $-y r$ & $55.0 \pm 15.8$ & $54.4 \pm 16.2$ & 0.42 \\
\hline Median & 56 & 55 & \\
\hline Range & $18-93$ & $18-97$ & \\
\hline Female sex — no. (\%) & $535(42.0)$ & $520(41.1)$ & 0.66 \\
\hline Race - no. $(\%) \dagger$ & & & 0.14 \\
\hline White & $1212(95.2)$ & $1195(94.4)$ & \\
\hline Black & $36(2.8)$ & $31(2.4)$ & \\
\hline Asian & $25(2.0)$ & $40(3.2)$ & \\
\hline Weight $-\mathrm{kg}$ & $85.5 \pm 19.2$ & $84.2 \pm 18.3$ & 0.10 \\
\hline Median & 84 & 82 & \\
\hline Range & $38-175$ & $39-161$ & \\
\hline Body-mass indext & $28.9 \pm 5.7$ & $28.4 \pm 5.5$ & 0.03 \\
\hline Estimated creatinine clearance $-\mathrm{ml} / \mathrm{min} \mathbb{}$ & $105.8 \pm 40.7$ & $104.4 \pm 39.9$ & 0.40 \\
\hline Type of index event — no. (\%) & & & 0.96 \\
\hline Deep-vein thrombosis only & $880(69.1)$ & $869(68.6)$ & \\
\hline Pulmonary embolism only & $270(21.2)$ & $271(21.4)$ & \\
\hline Both deep-vein thrombosis and pulmonary embolism & $121(9.5)$ & $124(9.8)$ & \\
\hline Neither deep-vein thrombosis nor pulmonary embolism & $2(0.2)$ & $2(0.2)$ & \\
\hline Cancer - no. (\%) & $64(5.0)$ & $57(4.5)$ & 0.60 \\
\hline Previous venous thromboembolism — no. (\%) & $327(25.7)$ & $322(25.4)$ & 0.92 \\
\hline \multicolumn{4}{|l|}{ Parenteral anticoagulation } \\
\hline \multicolumn{4}{|l|}{ Treatment before randomization — days } \\
\hline Median & 3.0 & 3.0 & \\
\hline Interquartile range & $2.0-4.0$ & $2.0-4.0$ & \\
\hline \multicolumn{4}{|c|}{ Treatment after randomization, in the single-dummy phase - days $\|$} \\
\hline Median & 6.0 & 6.0 & \\
\hline Interquartile range & $5.0-8.0$ & $5.0-8.0$ & \\
\hline Unfractionated heparin — no. (\%) & $144(11.3)$ & $164(13.0)$ & \\
\hline Low-molecular-weight heparin — no. (\%) & $1138(89.4)$ & $1148(90.7)$ & \\
\hline Fondaparinux - no. (\%) & $50(3.9)$ & $36(2.8)$ & \\
\hline \multicolumn{4}{|l|}{ Double-dummy phase*** } \\
\hline Exposure to study drug - days & $163.4 \pm 50.3$ & $163.9 \pm 50.2$ & \\
\hline Adherence to study regimen - no. (\%) & $1248(98.0)$ & $1234(97.5)$ & \\
\hline Percent of the time that INR was in the therapeutic range & NA & $59.9 \pm 22.9$ & \\
\hline
\end{tabular}

* Plus-minus values are means \pm SD. The numbers in the two groups represent the number of patients treated with dabigatran or warfarin, rather than the number assigned to the treatment (one patient who was assigned to receive dabigatran mistakenly received warfarin during the entire study). The $P$ values were calculated with the use of Student's t-test for creatinine clearance, the Wilcoxon-Mann-Whitney test for age and weight, Fisher's exact test for sex, cancer, and previous venous thromboembolism, and the chi-square test by class for race and type of index event. NA denotes not applicable.

$\dagger$ Race was determined by the investigator.

The body-mass index is the weight in kilograms divided by the square of the height in meters.

$\int$ Creatinine clearance was estimated according to the Cockcroft-Gault method.

9 In the case of two patients in each group, the diagnosis of venous thromboembolism was made locally and was subsequently not confirmed by the central adjudication committee.

\| In the single-dummy phase, patients received a parenteral anticoagulant agent and warfarin or warfarin-like placebo. Some patients received more than one parenteral anticoagulant during this phase.

$* *$ In the 6-month double-dummy phase, patients received only the oral treatment (dabigatran and warfarin-like placebo or warfarin and dabigatran-like placebo). Adherence was assumed if a pill count of dabigatran or the dabigatran placebo indicated an intake of between $80 \%$ and $120 \%$ of the prescribed dose. 
pared with warfarin, dabigatran was noninferior with regard to the prevention of recurrent or fatal venous thromboembolism $(\mathrm{P}<0.001$ for the criteria of both hazard ratio and the difference in risk). The results for the components of the primary end point are shown in Table 2. There was no significant difference in efficacy in predefined subgroups (see the Supplementary Appendix). Since noninferiority was established, we tested for superiority and found that it was not reached.

\section{SAFETY}

A total of 20 patients in the dabigatran group (1.6\%) and 24 patients in the warfarin group (1.9\%), had major bleeding episodes (hazard ratio, 0.82; 95\% CI, 0.45 to 1.48) (Fig. 2). The sites of major bleeding events in the dabigatran group were gastrointestinal (nine events), urogenital (five), intraarticular (one), intramuscular (one), or other (six), and the sites in the warfarin group were urogenital (six events), gastrointestinal (five), intraarticular (four), intracranial (three), intramuscular (three), or other (four); some patients had bleeding at more than one site. INR values were not obtained when bleeding occurred, in order to avoid unblinding of the treatment assignment. A total of 71 patients in the dabigatran group (5.6\%), as compared with 111 in the warfarin group (8.8\%), had major or clinically relevant nonmajor bleeding (hazard ratio, 0.63 ; $95 \% \mathrm{CI}, 0.47$ to 0.84 ; $\mathrm{P}=0.002$ ). The relative risk of bleeding with dabigatran as compared with warfarin was similar among the subgroups (data not shown). The only type of bleeding that showed a trend to higher incidence in the dabigatran group was gastrointestinal hemorrhage (Table 2).

There were 115 patients in the dabigatran group $(9.0 \%)$ and 86 patients in the warfarin group $(6.8 \%)$ who had an adverse event that led to discontinuation of the study drug (hazard ratio, 1.33; $95 \% \mathrm{CI}, 1.01$ to $1.76 ; \mathrm{P}=0.05)$. The number of patients who died, had an acute coronary syndrome, or had an elevation of the alanine aminotransferase level or the aspartate aminotransferase level exceeding three times the upper limit of normal while taking the study drug did not differ significantly between the treatment groups (Table 3). A combination of an alanine aminotransferase level exceeding three times the upper limit of normal and bilirubin exceeding twice the upper limit of normal was seen in two patients in the dabigatran group (of whom one had pancre-

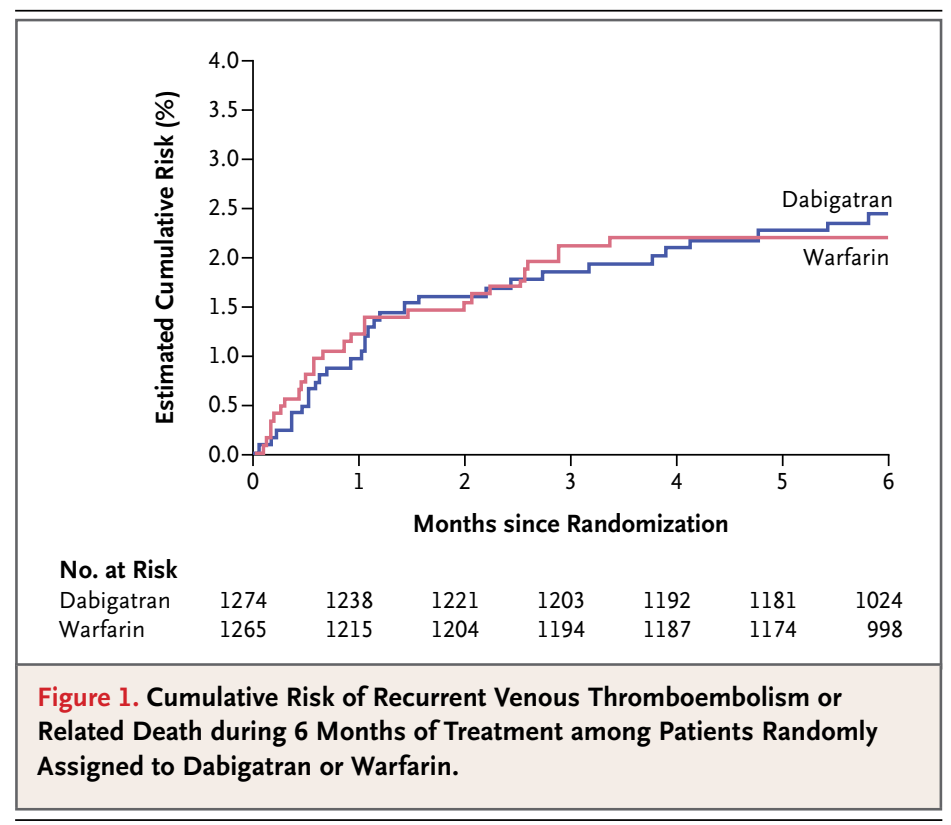

atic cancer and the other had cholangitis) and four patients in the warfarin group (of whom three had pancreatic cancer and one had uterine cancer with liver metastases). There were no significant differences between the two treatment groups in the frequency of any adverse events (Table 3) except for dyspepsia (2.9\% in the dabigatran group vs. $0.6 \%$ in the warfarin group, $\mathrm{P}<0.001$ ).

\section{DISCUSSION}

In this large, double-blind trial involving patients with acute venous thromboembolism, we compared 6 months of treatment with dabigatran, administered at a dose of $150 \mathrm{mg}$ twice daily, with warfarin therapy, after initial treatment with parenteral anticoagulation. We showed that dabigatran is noninferior to warfarin (when warfarin is doseadjusted to achieve and maintain an INR in the range of 2.0 to 3.0) in the prevention of recurrent events. Venous thromboembolism or related deaths occurred in 30 patients in the dabigatran group as compared with 27 patients in the warfarin group.

Dabigatran is an effective anticoagulant agent because direct thrombin inhibitors suppress thrombus growth by inhibiting both fibrin-bound and free thrombin, which converts fibrinogen to fibrin. ${ }^{14}$ In the RE-COVER study, treatment with dabigatran was as effective as warfarin therapy, which achieved INR values within the therapeu- 


\begin{tabular}{|c|c|c|c|}
\hline Outcome & $\begin{array}{l}\text { Dabigatran } \\
(\mathrm{N}=1274)\end{array}$ & $\begin{array}{l}\text { Warfarin } \\
(N=1265)\end{array}$ & $\begin{array}{l}\text { Hazard Ratio } \\
(95 \% \mathrm{CI}) *\end{array}$ \\
\hline \multicolumn{4}{|l|}{ Efficacy analysis $\hat{\dagger}$} \\
\hline \multicolumn{4}{|l|}{$\begin{array}{l}\text { Primary end point of venous thromboembolism or related death } \\
\qquad- \text { no. of subjects (\%) }\end{array}$} \\
\hline During the study period & $30(2.4)$ & $27(2.1)$ & $1.10(0.65-1.84)$ \\
\hline During the study period plus an additional 30-day follow-upt & $34(2.7)$ & $32(2.5)$ & $1.05(0.65-1.70)$ \\
\hline \multicolumn{4}{|l|}{ Secondary end point — no. of subjects (\%) } \\
\hline Symptomatic deep-vein thrombosis & $16(1.3)$ & $18(1.4)$ & $0.87(0.44-1.71)$ \\
\hline Symptomatic nonfatal pulmonary embolism & $13(1.0)$ & $7(0.6)$ & $1.85(0.74-4.64)$ \\
\hline Death related to venous thromboembolism & $1(0.1)$ & $3(0.2)$ & $0.33(0.03-3.15)$ \\
\hline All deaths & $21(1.6)$ & $21(1.7)$ & $0.98(0.53-1.79)$ \\
\hline \multicolumn{4}{|l|}{ Safety analysis [} \\
\hline Major bleeding event — no. of subjects (\%) & $20(1.6)$ & $24(1.9)$ & $0.82(0.45-1.48)$ \\
\hline Fatal event - no. of events & 1 & 1 & \\
\hline Bleeding into critical organ - no. of events & 1 & 9 & \\
\hline Intracranial & 0 & 3 & \\
\hline Hemarthrosis & 1 & 5 & \\
\hline Hemoptysis & 0 & 1 & \\
\hline $\begin{array}{l}\text { Event resulting in fall in hemoglobin level or need for blood } \\
\text { transfusions - no. of subjects (\%) }\end{array}$ & $20(1.6)$ & $18(1.4)$ & \\
\hline $\begin{array}{l}\text { Major or clinically relevant nonmajor bleeding event — no. of } \\
\text { subjects (\%) }\end{array}$ & $71(5.6)$ & $111(8.8)$ & $0.63(0.47-0.84)$ \\
\hline Any bleeding event - no. of subjects (\%) & $205(16.1)$ & 277 (21.9) & $0.71(0.59-0.85)$ \\
\hline
\end{tabular}

Site of bleeding event - no. of events\|

$\begin{array}{lrr}\text { Intracranial } & 0 & 3 \\ \text { Intraocular*** } & 8 & 9 \\ \text { Retroperitoneal } * * * & 4 & 1 \\ \text { Intraarticular or intramuscular } & 8 & 27 \\ \text { Gastrointestinal } & 53 & 35 \\ \text { Urogenital } & 53 & 95 \\ \text { Nasal*** } & 40 & 107 \\ \text { Other } & 137 & 205\end{array}$

* The hazard ratio was estimated with the use of the Cox model, including treatment, active cancer at baseline, symptomatic pulmonary embolism at baseline, and the interaction between active cancer and symptomatic pulmonary embolism at baseline as factors.

$\dagger$ The efficacy analysis was based on the number of randomly assigned patients who received at least one dose of study drug and who had events during the 6-month treatment period, regardless of early discontinuation of study drug.

$¥$ The extension of the study period (to day 224) was prespecified as a primary end point for the hazard ratio analysis in the trial's statistical-analysis plan. Although the analysis includes events during the 30-day extension, it does not reflect the true incidence of the end point after anticoagulation was discontinued, since more than 500 patients in each group were enrolled in an extended-treatment study with double-blind design, and additional patients received openlabel anticoagulants.

$\int$ The safety analysis of bleeding events was performed on the basis of the number of patients treated with dabigatran (1273) or warfarin (1266), rather than the number assigned to the treatment (1 patient who was assigned to receive dabigatran mistakenly received warfarin instead throughout the study). Events that occurred during the 6-month treatment period plus a 6-day washout period were included.

9 Included in this category were patients in whom there was a reduction in hemoglobin level of at least $20 \mathrm{~g}$ per liter or who required a transfusion of at least 2 units of whole blood or red cells.

|| Patients may have had more than one type of bleeding event.

*** None of these bleeding episodes were adjudicated as major bleeding. 
tic INR range $60 \%$ of the time - a rate that is consistent with good-quality management of warfarin dosing. ${ }^{15}$

The rates of bleeding with dabigatran were similar to or lower than those with warfarin. There were 20 major bleeding events in the dabigatran group as compared with 24 in the warfarin group, and there were fewer episodes of nonmajor bleeding with dabigatran than with warfarin. These findings are consistent with data on bleeding from the Randomized Evaluation of Long-Term Anticoagulation Therapy trial (RE-LY; NCT00262600), ${ }^{8}$ in which open-label dabigatran and warfarin therapies were compared in patients with atrial fibrillation. In the RE-LY trial, major bleeding and intracranial bleeding were less frequent among patients receiving dabigatran (at a dose of $150 \mathrm{mg}$ twice daily) than among those receiving warfarin, and in both the RE-LY trial and the current study, the incidence of nonmajor bleeding was reduced with dabigatran. Clinically relevant nonmajor bleeding is an important factor to consider, since its management is time-consuming and costly ${ }^{16}$ and since bleeding is the most important reason for the perception of decreased health and quality of life among patients treated with warfarin. ${ }^{17}$

In trials of the only previously available oral direct thrombin inhibitor, ximelagatran, noninferiority with respect to warfarin was achieved in the treatment of recurrent venous thromboembolism, and rates of major bleeding were similar in both treatment groups. ${ }^{18}$ However, toxic effects to the liver occurred with prolonged exposure to ximelagatran. ${ }^{19}$ In contrast, there was no evidence of hepatic toxic events associated with dabigatran in the current study or in studies in which it was used for other indications. 7,8,20 Dyspepsia, which was observed in $3 \%$ of the patients in the dabigatran group, was the only adverse event attributable to dabigatran in our study. The mechanism for increased dyspepsia among patients receiving dabigatran therapy is currently unknown. None of the other adverse events differed significantly between the treatments.

In the current study, the average age of the patients was 55 years, more than $90 \%$ had a creatinine clearance that was higher than $50 \mathrm{ml}$ per minute, and $95 \%$ of the study population was white. Therefore, additional studies should be performed that involve patients whose baseline characteristics differ markedly from this population. A limitation of the study is that the first dose of

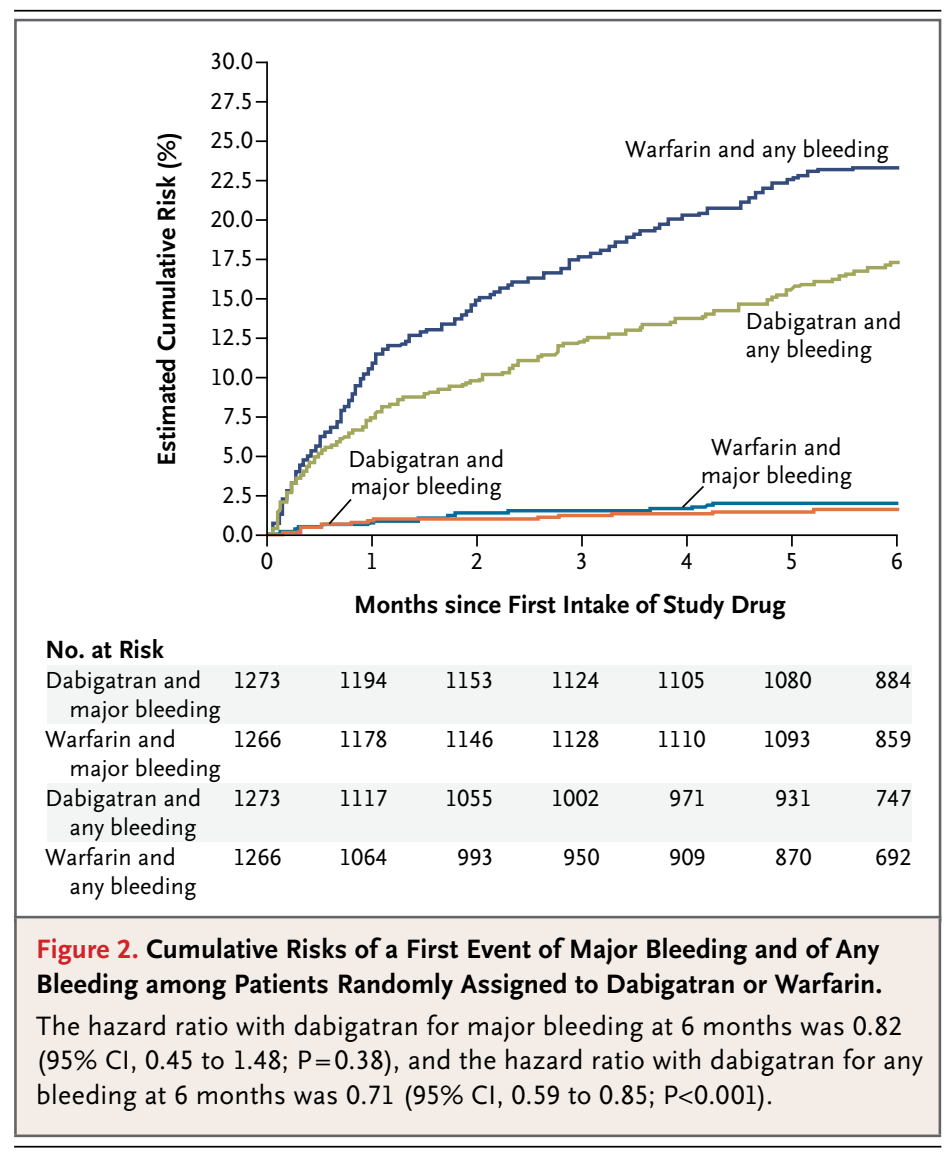

dabigatran, which has a rapid onset of effect, was given only after initial parenteral anticoagulation therapy had been administered for a median of 9 days (interquartile range, 8 to 11). Thus, there are no data to support the use of dabigatran monotherapy for acute venous thromboembolism. We chose to treat patients in the dabigatran group with initial parenteral anticoagulation, because treatment of acute venous thromboembolism with ximelagatran alone appeared to be associated with a higher early rate of recurrent venous thromboembolism than did treatment with enoxaparin and warfarin. ${ }^{18}$ The median total duration of parenteral therapy of 9 days is longer than the typical duration of treatment when warfarin and heparin are started simultaneously; however, the duration of heparin therapy ( 5 days as compared with 10 days) has not been shown to influence the efficacy of long-term anticoagulation. ${ }^{21,22}$

Our trial provides data to support dabigatran as a fixed-dose oral treatment for acute deep-vein thrombosis and pulmonary embolism. For pa- 


\begin{tabular}{|c|c|c|c|c|c|}
\hline \multirow[t]{2}{*}{ Event } & \multicolumn{2}{|c|}{ Dabigatran } & \multicolumn{2}{|c|}{ Warfarin } & \multirow[t]{2}{*}{ P Value $i$} \\
\hline & $\begin{array}{c}\text { Double-Dummy } \\
\text { Phase } \\
(\mathrm{N}=1226)\end{array}$ & $\begin{array}{l}\text { Total Period } \\
\text { of Treatment } \\
(\mathrm{N}=1273)\end{array}$ & $\begin{array}{c}\text { Double-Dummy } \\
\text { Phase } \\
(\mathrm{N}=1214)\end{array}$ & $\begin{array}{l}\text { Total Period } \\
\text { of Treatment } \\
(\mathrm{N}=1266)\end{array}$ & \\
\hline Any event - no. of subjects (\%) & $770(62.8)$ & $844(66.3)$ & $792(65.2)$ & $856(67.6)$ & 0.51 \\
\hline Serious event - no. of subjects (\%) & $147(12.0)$ & $165(13.0)$ & $133(11.0)$ & $150(11.8)$ & 0.43 \\
\hline $\begin{array}{l}\text { Event leading to discontinuation of study drug - } \\
\text { no. of subjects (\%) }\end{array}$ & $97(7.9)$ & $115(9.0)$ & $79(6.5)$ & $86(6.8)$ & 0.05 \\
\hline \multicolumn{6}{|l|}{$\begin{array}{l}\text { Events with an incidence of at least } 3 \% \text { - no. of } \\
\text { subjects (\%) }\end{array}$} \\
\hline Headache & $60(4.9)$ & $79(6.2)$ & $64(5.3)$ & $88(7.0)$ & 0.50 \\
\hline Pain in extremity & $59(4.8)$ & $64(5.0)$ & $69(5.7)$ & $71(5.6)$ & 0.57 \\
\hline Nausea & $43(3.5)$ & $49(3.8)$ & $43(3.5)$ & $58(4.6)$ & 0.41 \\
\hline Diarrhea & $46(3.8)$ & $57(4.5)$ & $34(2.8)$ & $38(3.0)$ & 0.06 \\
\hline Nasopharyngitis & $47(3.8)$ & $50(3.9)$ & $53(4.4)$ & $54(4.3)$ & 0.74 \\
\hline Dyspnea & $33(2.7)$ & $41(3.2)$ & 47 (3.9) & $53(4.2)$ & 0.24 \\
\hline Back pain & $42(3.4)$ & $46(3.6)$ & $44(3.6)$ & $50(3.9)$ & 0.73 \\
\hline Arthralgia & $45(3.7)$ & $48(3.8)$ & $30(2.5)$ & $33(2.6)$ & 0.12 \\
\hline Peripheral edema & $41(3.3)$ & $43(3.4)$ & $45(3.7)$ & $48(3.8)$ & 0.65 \\
\hline Dyspepsia & $36(2.9)$ & $39(3.1)$ & $7(0.6)$ & $9(0.7)$ & $<0.001$ \\
\hline \multicolumn{6}{|l|}{ Acute coronary syndrome - no. of subjects (\%)』 } \\
\hline Any & $4(0.3)$ & $5(0.4)$ & $3(0.2)$ & $3(0.2)$ & 0.73 \\
\hline Myocardial infarction & $3(0.2)$ & $4(0.3)$ & $2(0.2)$ & $2(0.2)$ & 0.69 \\
\hline \multicolumn{6}{|l|}{$\begin{array}{l}\text { Abnormal liver-function tests - no. of subjects/ } \\
\text { total no. (\%) }\end{array}$} \\
\hline AST $>3 \times U L N$ & $33 / 1204(2.7)$ & $38 / 1220(3.1)$ & $20 / 1188(1.7)$ & $25 / 1199(2.1)$ & 0.14 \\
\hline $\mathrm{ALT}>3 \times \mathrm{ULN}$ & $35 / 1204(2.9)$ & $42 / 1220(3.4)$ & $42 / 1188(3.5)$ & $46 / 1199(3.8)$ & 0.68 \\
\hline ALT $>3 \times$ ULN plus bilirubin $>2 \times U L N$ & $2 / 1195(0.2)$ & $2 / 1055(0.2)$ & $4 / 1182(0.3)$ & $4 / 1106(0.4)$ & 0.69 \\
\hline
\end{tabular}

* In the double-dummy phase, patients received only the oral treatment (dabigatran and warfarin-like placebo or warfarin and dabigatran-like placebo). The total period of treatment included the single-dummy phase (in which patients received a parenteral anticoagulant agent and warfarin or warfarin-like placebo) and the double-dummy phase. A 6-day washout period was included in both cases. ALT denotes alanine aminotransferase, AST aspartate aminotransferase, and ULN upper limit of normal.

$\uparrow$ The $\mathrm{P}$ values are for the comparison between the two groups during the total treatment period. The $\mathrm{P}$ value for adverse events leading to discontinuation of treatment was calculated with the use of the Cox model, including treatment, active cancer at baseline, symptomatic pulmonary embolism at baseline, and the interaction between active cancer and symptomatic pulmonary embolism at baseline as factors. The $P$ values for acute coronary syndrome, myocardial infarction, and ALT exceeding three times the upper limit of normal plus bilirubin exceeding two times the upper limit of normal were calculated with the use of Fisher's exact test. The $P$ values for the rest of the events were calculated with the use of the chi-square test.

$\mp$ Bleeding events are not presented in this table; epistaxis and hematuria occurred in $3 \%$ or more of patients in the warfarin group.

$\int$ Included in this category are acute coronary syndromes that were classified as definite or likely by the independent adjudication committee.

tients and health care providers, dabigatran is a far more convenient drug than warfarin because it has no known interactions with foods and minimal interactions with other drugs and therefore does not require routine blood-coagulation testing.

Supported by Boehringer Ingelheim.

Dr. Schulman reports receiving consulting fees from AstraZeneca, Bayer HealthCare, Boehringer Ingelheim, GlaxoSmith-
Kline, and Sanofi-Aventis, lecture fees from LEO Pharma, Sanofi-Aventis, and Boehringer Ingelheim, and grant support from Bayer HealthCare; Dr. Kearon, consulting fees from Boehringer Ingelheim; Dr. Kakkar, consulting fees and honoraria from Boehringer Ingelheim, Bayer Schering Pharma, SanofiAventis, Bristol-Myers Squibb, Pfizer, ARYx Therapeutics, Canyon Pharmaceuticals, and Eisai, lecture fees from Sanofi-Aventis, Bayer Schering Pharma, Boehringer Ingelheim, GlaxoSmithKline, Eisai, and Pfizer, and grant support from Sanofi-Aventis, Boehringer Ingelheim, Pfizer, and Bayer Schering Pharma; Dr. 
Mismetti, consulting fees and lecture fees from Boehringer Ingelheim, Sanofi-Aventis, and GlaxoSmithKline; Dr. Schellong, lecture fees and consulting fees from Bayer HealthCare, Boehringer Ingelheim, and GlaxoSmithKline and consulting fees from Sanofi-Aventis; Dr. Eriksson, consulting fees and lecture fees from Boehringer Ingelheim, Pfizer, AstraZeneca, Bayer HealthCare, LEO Pharma, and Sanofi-Aventis; and Dr. Gold- haber, clinical research support from Sanofi-Aventis, BristolMyers Squibb, and Boehringer Ingelheim, and consulting fees from Sanofi-Aventis, Boehringer Ingelheim, Merck, MEDRAD Interventional/Possis, Bristol-Myers Squibb, Genentech, and Medscape. Mr. Baanstra and Dr. Schnee report being employees of Boehringer Ingelheim. No other potential conflict of interest relevant to this article was reported.

APPENDIX

Members of the RE-COVER Study Group are as follows: Steering Committee: S. Schulman (chair), H. Eriksson, S. Goldhaber, A. Kakkar, C. Kearon, P. Mismetti, S. Schellong. Data and Safety Monitoring Board: E. Minar (chair), D. Bergqvist, J. Tijssen. Independent Central Adjudication Committee for venous thromboembolism, bleeding and death: M. Prins (chair), H. Büller, J. Otten. Acute Coronary Syndrome Adjudication Committee: M. Prins (chair), R. Peters, M. Mac Gillavry, H. Büller. Hepatology Review Panel: S. Pol (chair), A. Burroughs, I. Gilmore. Principal Investigators: Argentina: J. Bluguermann, O. Carlevaro, L. Dipaola, P. Gitelman, D. Santos, P. Schygiel; Australia: R. Baker, P. Blombery, A. Gallus, E. Gan, H. Gibbs, H. Salem; Austria: M. Baghestanian, E. Pilger, W. Sturm; Belgium: E. Debing, A. Gadisseur, P. Hainaut, P. Verhamme, J.-C. Wautrecht, M. Zicot; Brazil: J.M. Annichino Bizzachi, G. Araujo, J. Dalmo De Araujo, F.M. Duarte Brandão Panico, Y. Nagato, A.H. Pereira, P. Puech Leao, E. Ramaciotti, R.C. Rocha Moreira, J. Timi; Canada: D. Anderson, M. Crowther, S. Dolan, J. Eikelboom, F. Spencer, M. Game, S. Kahn, J. Kassis, C. Kearon, P. Klinke, M. Kovacs, A. Milot, B. Ritchie, M. Rodger, S. Solymoss, J. Villeneuve, E. Yeo; Czech Republic: P. Cervinka, M. Homza, P. Hrdy, Z. Klimsa, P. Lang, R. Maly, I. Oral, P. Reichert, J. Spinar, P. Varejka, J. Vladimir; Denmark: J. Brønnum-Schou, S. Jensen, S.E. Jensen, K.S. Kristensen, H. Nielsen, O. Wiemann; France: V. Bost, A. Buchmuller, K. Guillot, P. Laurent, F. Lecomte, D. Mottier, I. Quere, D. Wahl; Germany: J. Beyer, A. Dormann, U. Hoffmann, M. Maier, A. Mietaschk, S. Schellong; Greece: K. Katsenis, C. Klonaris, C. Liappis; Hungary: G. Acsady, I. Berhes, Z. Boda, K. Farkas, J. Jakucs, L. Kollar, L. Matyas, M. Riba, M. Sereg; India: R. Aggarwal, D. Banker, A. Bharani, M. Gadkari, J. Hiremath, A. Jain, S. Kareem, S. Lyengar, R. Parakh, N. Sekar, A. Srinivas, K. Suresh, T. Vujay; Israel: B. Brenner, S. Efrati, M. Elias, D. Gavish, E. Grossman, M. Lahav, M. Lishner, D. Zeltser; Italy: G. Agnelli, C. Cimminiello, G. Palareti, P. Prandoni, M. Santonastaso, M. Silingardi; Mexico: E. Aldrett Lee, J.M. Fontes Andrade, J. Jaurrieta Valles; the Netherlands: D. Biesma, A. Dees, R. Fijnheer, K. Hamulyak, M.H.H. Kramer, F.W.G. Leebeek, L. Lieverse, M.T. Nurmohamed; New Zealand: S. Chunilal, S. Jackson, P. Ockelford, M. Smith; Norway: A.M. Njaastad, P.M. Sandseth, A. Tveit, A. Waage; Portugal: J. Barata, M. Capitao, F.E. Fernandes, A. Leitão, L. Providência; Russia: D.I. Alohin, S. Belentsov, M. Chernyatina, A. Chernyavsky, A. Fokin, A. Gubenko, V. Alexander V. Guz, I. Katelnitsky, I. Katelnitsky, A.A.A. Khamitov, A. Khitaryan, G. Khubulava, I. Mikhailov, V. Shkurin, I. Staroverov, A. Tchumakov, A. Zaporozhsky; Slovakia: T. Duris, P. Poliacik, V. Spisak, M. Szentivanyi, V. Zubek; South Africa: D. Adler, D. Kelbe, D. Le Roux, A. Pieterse, R. Routier, R. Siebert, B. Sloane, C. Smith, H. Van Rensburg; Spain: J. Del Toro, M.J. García-Fuster, J. Mateo, M. Monreal, J.A. Nieto, P. Sánchez-Molini, C. Sedano, J. Trujillo, R. Valle, J. Villalta; Sweden: J. Aagesen, A. Carlsson, H. Eriksson, L. Johansson, G. Lärfars, P. Lindmarker, U. Säfvenberg, A. Själander; Turkey: U. Bengisun, T. Calkavur, E. Eren, S. Karahan, M. Kurtoglu, U. Sakinci; Ukraine: A. Gubka, V. Mishalov, O. Skupyy; United Kingdom: A. Cohen, D. Keeling, P. Kesteven, P. MacCallum, R. Maclean, P. Shah, H. Watson; United States: A. Bartkowiak, E. Bolster, W.C. Botnick, B. Burnett, A. Chervu, A.J. Comerota, N.M. Dy, F.A. Fulco, J.R. Gossage, S. Kaatz, B. Lahiri, R.G. Lerner, J.A. Masson, S. Moll, M. Morganroth, K. Patel, R. Paulson, R. Powell, R. Samson, A. Seibert, A. Spyropoulos, P.S. Vrooman, Jr.

\section{REFERENCES}

1. Oger E. Incidence of venous thromboembolism: a community-based study in Western France. Thromb Haemost 2000, 83:657-60.

2. Spencer FA, Emery C, Lessard D, et al. The Worcester Venous Thromboembolism study: a population-based study of the clinical epidemiology of venous thromboembolism. J Gen Intern Med 2006;21: 722-7.

3. Kearon C, Kahn SR, Agnelli G, Goldhaber S, Raskob GE, Comerota AJ. Antithrombotic therapy for venous thromboembolic disease: American College of Chest Physicians Evidence-Based Clinical Practice Guidelines (8th Edition). Chest 2008;133:Suppl:454S-545S.

4. Ansell J, Hirsh J, Hylek E, Jacobson A, Crowther M, Palareti G. Pharmacology and management of the vitamin $\mathrm{K}$ antagonists: American College of Chest Physicians Evidence-Based Clinical Practice Guidelines (8th Edition). Chest 2008;133: Suppl:160S-198S.

5. Baetz BE, Spinler SA. Dabigatran etexilate: an oral direct thrombin inhibitor for prophylaxis and treatment of thromboembolic diseases. Pharmacotherapy 2008;28: 1354-73.

6. Eriksson BI, Dahl OE, Rosencher N, et al. Oral dabigatran etexilate vs. subcutaneous enoxaparin for the prevention of venous thromboembolism after total knee replacement: the RE-MODEL randomized trial. J Thromb Haemost 2007;5:2178-85. 7. Eriksson BI, Dahl OE, Rosencher N, et al. Dabigatran etexilate versus enoxaparin for prevention of venous thromboembolism after total hip replacement: a randomised, double-blind, non-inferiority trial. Lancet 2007;370:949-56.

8. Connolly SJ, Ezekowitz MD, Yusuf S, et al. Dabigatran versus warfarin in patients with atrial fibrillation. $\mathrm{N}$ Engl J Med 2009;361:1139-51.

9. Schulman S, Kearon C. Definition of major bleeding in clinical investigations of antihemostatic medicinal products in non-surgical patients. J Thromb Haemost 2005;3:692-4.

10. Holmgren K, Andersson G, Fagrell B, et al. One-month versus six-month thera- py with oral anticoagulants after symptomatic deep vein thrombosis. Acta Med Scand 1985;218:279-84.

11. Levine MN, Hirsh J, Gent M, et al. Optimal duration of oral anticoagulant therapy: a randomized trial comparing four weeks with three months of warfarin in patients with proximal deep vein thrombosis. Thromb Haemost 1995;74:606-11. 12. Schulman S, Lockner D, Juhlin-Dannfelt $\mathrm{A}$. The duration of oral anticoagulation after deep vein thrombosis: a randomized study. Acta Med Scand 1985;217: 547-52.

13. Schulman S, Rhedin AS, Lindmarker $\mathrm{P}$, et al. A comparison of six weeks with six months of oral anticoagulant therapy after a first episode of venous thromboembolism. N Engl J Med 1995;332:1661-5.

14. Gross PL, Weitz JI. New antithrombotic drugs. Clin Pharmacol Ther 2009;86: 139-46.

15. Rose AJ, Ozonoff A, Henault LE, Hylek EM. Warfarin for atrial fibrillation in community-based practise. J Thromb Haemost 2008;6:1647-54. 
16. Gould MK, Dembitzer AD, Sanders GD, Garber AM. Low-molecular-weight heparins compared with unfractionated heparin for treatment of acute deep venous thrombosis: a cost-effectiveness analysis. Ann Intern Med 1999;130:789-99.

17. Lancaster TR, Singer DE, Sheehan MA, et al. The impact of long-term warfarin therapy on quality of life: evidence from a randomized trial. Arch Intern Med 1991;151:1944-9.

18. Fiessinger JN, Huisman MV, Davidson $\mathrm{BL}$, et al. Ximelagatran vs low-molecular- weight heparin and warfarin for the treatment of deep vein thrombosis: a randomized trial. JAMA 2005;293:681-9.

19. Schulman $S$, Wåhlander $K$, Lundström T, Clason SB, Eriksson H. Secondary prevention of venous thromboembolism with the oral direct thrombin inhibitor ximelagatran. N Engl J Med 2003;349: 1713-21.

20. Ezekowitz MD, Reilly PA, Nehmiz G, et al. Dabigatran with or without concomitant aspirin compared with warfarin alone in patients with nonvalvular atrial fibril- lation (PETRO Study). Am J Cardiol 2007;100:1419-26.

21. Gallus A, Jackaman J, Tillett J, Mills W, Wycherley A. Safety and efficacy of warfarin started early after submassive venous thrombosis or pulmonary embolism. Lancet 1986;2:1293-6.

22. Hull RD, Raskob GE, Rosenbloom D, et al. Heparin for 5 days as compared with 10 days in the initial treatment of proximal venous thrombosis. $\mathrm{N}$ Engl $\mathrm{J}$ Med 1990;322:1260-4.

Copyright (c) 2009 Massachusetts Medical Society.

ELECTRONIC ACCESS TO THE JOURNAL'S CUMULATIVE INDEX

At the Journal's site on the World Wide Web (NEJM.org), you can search an index of all articles published since January 1975 (abstracts 1975-1992, full text 1993-present). You can search by author, key word, title, type of article, and date. The results will include the citations for the articles plus links to the full text of articles published since 1993. For nonsubscribers, time-limited access to single articles and 24-hour site access can also be ordered for a fee through the Internet (NEJM.org). 